Review Article

\title{
Research Progress and Engineering Applications of Stainless Steel-Reinforced Concrete Structures
}

\author{
Jian Yuan (iD and Zhinan Ou \\ College of Civil Engineering, Central South University of Forestry and Technology, Changsha 410004, China \\ Correspondence should be addressed to Jian Yuan; yuanjian0571@163.com
}

Received 3 June 2021; Accepted 3 September 2021; Published 17 September 2021

Academic Editor: Jin Kook Kim

Copyright (c) 2021 Jian Yuan and Zhinan Ou. This is an open access article distributed under the Creative Commons Attribution License, which permits unrestricted use, distribution, and reproduction in any medium, provided the original work is properly cited.

\begin{abstract}
The durability of concrete structures can effectively be enhanced by using stainless steel rather than ordinary steel reinforcements under harsh service conditions. Because the basic mechanical properties and stress-strain relationship of stainless steel reinforcements obviously differ from those of ordinary steel reinforcements, the current design codes for reinforced concrete structures are not appropriate for stainless steel-reinforced concrete. On the basis of the research works reported in the past decades, this paper systematically summarizes and analyzes the mechanical properties and corrosion resistance of stainless steel reinforcements, the properties of the bond between stainless steel reinforcements and concrete, the mechanical properties of stainless steel-reinforced concrete members, and the application of stainless steel reinforcements in practical engineering and proposes relevant problems which should be examined further. It is suggested that the design theory of stainless steel-reinforced concrete structures should be further improved to take full advantage of these structures.
\end{abstract}

\section{Introduction}

Given that concrete structures with ordinary steel reinforcements can maintain good working performance under nonextreme conditions, they generally require no maintenance within the designed service life. Nonetheless, in various types of structures such as cross-sea bridges, offshore structures, underground parking lots, industrial or medical buildings with corrosive media, and highway bridges using sodium chloride as the deicing salt, the steel reinforcements may experience corrosion due to poor environmental conditions or improper using methods. It has been reported that the cost of the maintenance of concrete structures due to steel reinforcement corrosion is up to $\$ 100$ billion each year worldwide [1]. Moreover, the maintenance cost of roads and bridges in China due to corrosion issues was about 10.89 billion yuan in 2014 [2]. Therefore, the corrosion of steel reinforcements not only affects the safety and durability of concrete structures but also causes huge economic losses.

The traditional measures to prevent the corrosion of steel bars chiefly include coating the surface of concrete, increasing the thickness of the concrete cover, using highperformance concrete to block the penetration path of corrosive media, galvanizing steel bars, coating the surface of steel bars with epoxy, utilizing antirust retardant agents for steel bars, and employing the cathodic protection of steel bars. However, the above measures can only extend the service life of structures by about 20 years and cannot fundamentally solve the problem of steel reinforcement corrosion. Stainless steel bars can rely on the passive film formed on their surface to block the anode process, thereby improving the chemical stability of the metal to resist corrosion [3, 4]. Although stainless steel bars are expensive, their mechanical strength is generally high, making them suitable for the joint use with high-performance concrete. They have minimal requirements for the thickness of the concrete cover and the limit on the maximum crack width, which significantly reduces the self-weight of concrete structures and the amount of steel bars, facilitates the construction process, and saves labor costs. In the service process, stainless steel-reinforced concrete structures can also avoid or remarkably reduce the costs of structural 
strengthening [3, 5-9]. Generally, it is reasonable to use stainless steel bars instead of ordinary steel bars in structural members with a high risk of corrosion as the overall cost during the entire life cycle of the project does not increase significantly.

Some countries have listed stainless steel bars as materials for concrete structure projects [3, 10-16]. For example, China issued the "Guide to Durability Design and Construction of Concrete Structures" in 2004 [17] and stipulated that stainless steel reinforcement can be used in especially important projects which require more than one hundred years of service life in particularly severe corrosive environments. Although the price of stainless steel bars is about 6-10 times that of ordinary steel bars, they have a long service life and can save a large amount of maintenance costs. Thus, it is economical and reasonable to use stainless steel bars under certain conditions. However, the understanding of the mechanical properties of concrete members reinforced with stainless steel bars is still lacking; hence, the relevant structural design and the subsequent maintenance lack theoretical basis, and engineers have to follow the structural specifications designed for ordinary steel-reinforced concrete. Consequently, it is difficult to fully exploit the potential of stainless steel-reinforced concrete structures, and this conservative approach may pose a security risk.

At present, the studies on stainless steel-reinforced concrete structures can chiefly be divided into four categories: the mechanical properties and corrosion resistance of stainless steel bars, the characteristics of the bond between stainless steel bars and concrete, the mechanical properties of the structural members reinforced with stainless steel bars, and their engineering applications. In order to better promote the development of stainless steel-reinforced concrete structures, this paper systematically reviews the research development of stainless steel-reinforced concrete structures, analyzes the current problems, and suggests future research directions.

\section{Mechanical Properties and Corrosion Resistance of Stainless Steel Bars}

Stainless steel bars used in concrete chiefly refer to hotrolled, solid, and steel bars which are produced by using austenitic stainless steel or austenitic-ferritic stainless steel as the raw materials. The magnetic permeability of austenitic stainless steel bars is extremely low, so they can be used in buildings requiring high antimagnetic properties such as electronic manufacturing factories, which are sensitive to magnetic permeability, and military engineering buildings. Compared with ordinary steel, stainless steel has a lower elastic modulus; furthermore, although there is no obvious yield point and yielding platform in the stress-strain curve of stainless steel, it possesses significant strain hardening characteristics and high ductility [18-20]. Figure 1 delineates the stress-strain curves of ordinary steel and stainless steel [21], where $\sigma$ is the stress and $\varepsilon$ is the strain of steel. Figure 2 delineates the yield strength of the stainless steel is usually the stress value corresponding to the residual strain of $0.2 \%$. It demonstrates that the stress-strain curve of stainless steel

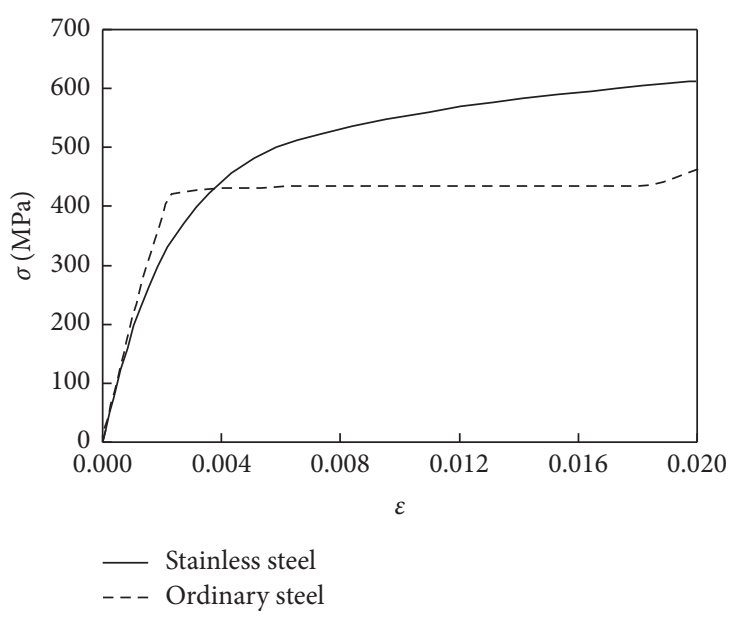

FIGURE 1: Stress-strain curves of ordinary steel and stainless steel.

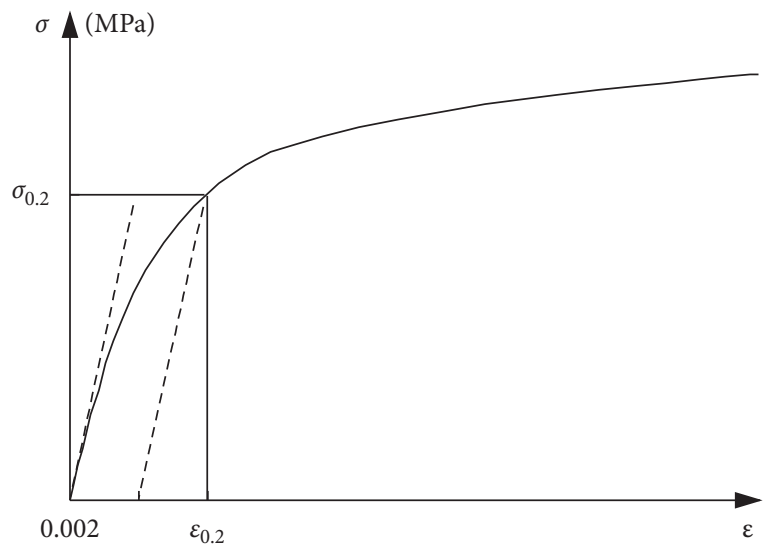

FIGURE 2: Yield strength of stainless steel.

has a highly nonlinear characteristic, and the proportional limit is much lower than the nominal yield strength. In addition, stainless steel offers good hysteretic performance [22-24] and high resistance to high and low temperatures [25-29]. The stress-strain curves of the stainless steel under tension and compression are also asymmetric and anisotropic, and these features become more noticeable with the progress of the cold working process [30].

Studies have further demonstrated that stainless steel materials enjoy the advantages of high strength, suitable ductility, and strong resistance to high and low temperatures $[4,31-36]$. The proportionality limit and elastic modulus of stainless steel bars are relatively low, and it has no obvious yielding platform. Its tensile strength is also much higher than its yield strength, and it can offer significant strainhardening characteristics. According to the experimental work of [34], the high-strength stainless steel bars have a significantly high ductility and low elastic modulus. In fact, the elastic modulus of stainless steel bars is only 0.69 times that of ordinary steel bars, while the total elongation under the maximum force of stainless steel bars is 1.7 times that of ordinary steel bars.

Moreover, stainless steel bars offer excellent corrosion resistance in $3.5 \% \mathrm{NaCl}$ solution [37-41]. For example, the 
results of a corrosion test lasted for more than two years proved that the rate of corrosion of stainless steel bars was lower than $2 \%$ of that of ordinary steel bars [37]. Another work found that the stainless steel bars in coral concrete were still in a passive state after 750 days, while the surface of ordinary steel bars experienced obvious corrosion [39]. It was also reported that the corrosion degree of stainless steel bars became higher with the increase in the strain level at a similar corrosion period [40, 41]. Islam et al. employed the linear polarization method and found that the ordinary steel bars in the concrete began to corrode in 2 weeks, while the stainless steel bars took 139 weeks to corrode in the same concentration of chloride ions [42]. Chen et al. reported that the critical concentration of the chloride ions for the corrosion of stainless steel bars was over 20 times higher than that of ordinary steel bars [43]. Jing et al. conducted research on the corrosion resistance of duplex stainless steel bars used in the Hong Kong-Zhuhai-Macao bridge and demonstrated that the critical concentration of chloride ions for the pitting corrosion of stainless steel bars in the simulated concrete pore solutions was between 3.9 and $3.95 \mathrm{~mol} / \mathrm{L}$, which was about 60 times higher than that of ordinary steel bars [44]. The research results of Ling confirmed that the critical value of the concentration of chloride ions for the corrosion of stainless steel bars in concrete pore solutions ranged from 3.0 to $3.5 \mathrm{~mol} / \mathrm{L}$, which was 75 times that of ordinary steel bars [45].

Moser et al. studied the corrosion resistance of different types of high-strength stainless steel bars in simulated alkaline and carbonated concrete pore solutions and found that all the specimens exhibited strong resistance to corrosion in alkaline solutions [46]. In another work, Van Niejenhuis et al. conducted a test to investigate whether stainless steel bars could resist the erosion by highly concentrated deicing salt and found that six different grades of stainless steel bars showed no signs of corrosion in crack-free concrete [47]. Similar works carried out 7 and 10 years of experimental research studies on the resistance of stainless steel bars and other types of steel bars to corrosion in chlorine-containing concrete; the results confirmed that the stainless steel bars did not show any signs of corrosion, while the other specimens were corroded to varying degrees and caused concrete cracking $[48,49]$. The research results of $\mathrm{Da}$ et al. demonstrated that the corrosion resistance of the stainless steel bars embedded in coral aggregate seawater concrete was higher than that of the coated steel bars, and the ordinary steel bars performed worst [50].

Zheng et al. used an artificial climate aging chamber to simulate the marine salt spray environment [51]. By carrying out an accelerated steel corrosion test, they found the corrosion status of stainless steel bars and ordinary steel bars which underwent the salt spray test for 57 days, as shown in Figure 3. It can be seen that the surface of the ordinary steel bars shows uniform corrosion, and the surface is full of rust pits after rust removal. However, stainless steel bars only show small corrosion pits in part, and no obvious corrosion products are detected; they basically resemble the new stainless steel bars. Further analysis found that the reduction in the strength of the ordinary steel bars was similar to the amount of the corrosion, and a brittle fracture occurred. However, no significant changes were found in the mechanical and processing properties of stainless steel bars. Thus, it can be concluded that the corrosion resistance of stainless steel bars is over 100 times higher than that of ordinary steel bars.

Regarding the galvanic corrosion properties of the stainless steel bars combined with ordinary steel bars, a number of studies show that (1) when ordinary steel bars are used as the cathode, there is a higher corrosion current in the anode, i.e., the stainless steel bars [52], (2) when both types of the steel bars are in a passive state, the galvanic couple is negligible [44, 53], and (3) when the stainless steel bars are in a passive state and the ordinary steel bars are activated, the overlap of the two types of the steel bars produces galvanic corrosion in the ordinary steel bars $[44,54,55]$. Therefore, measures must be taken to prevent the direct contact between stainless steel bars and ordinary steel bars so as to avoid galvanic corrosion.

In summary, stainless steel has good mechanical properties and strong resistance to corrosion, but there is still a lack of systematic research on analyzing its nature, e.g., its constitutive properties. In view of the high initial cost of stainless steel bars, it is necessary to fully exploit its remarkable strain hardening characteristics and high ductility in the design process. Currently, artificially configured corrosive solutions are used to conduct the corrosion resistance test on stainless steel bars through various test processes and methods. Different corrosive solutions and corrosion periods have different effects on the resistance of stainless steel bars to corrosion. Moreover, the difference between the laboratory corrosion environment settings and the actual service environment is still unclear, so it is essential to standardize the testing methods and the result evaluation system in order to systematically research the resistance of stainless steel bars to corrosion.

\section{Performance of Bond between Stainless Steel Bars and Concrete}

The behavior of the bond between steel bars and concrete, which is chiefly composed of three types of forces, namely, the chemical adhesive force, the friction force, and the mechanical bite force, is the key to fully exploit the mechanical properties of steel bars in concrete members. These forces are influenced by many factors such as the material characteristics of concrete and steel bars and the relationship between them. Among these factors, the influence of the material properties of steel bars is largely related to their diameter, rib shape, yield strength, and postyield. The relationship between steel bars and concrete is also reflected in the thickness of the concrete cover and the steel bar space. According to the types of specimens, the test methods for studying the performance of the bond between steel bars and concrete primarily include the central pullout test, the beam test, and the two-end tension test. The central pullout test is the most widely used technique for examining the behavior of the bond between steel bars and concrete. Although the central pullout test is relatively simple, the regulations on the 


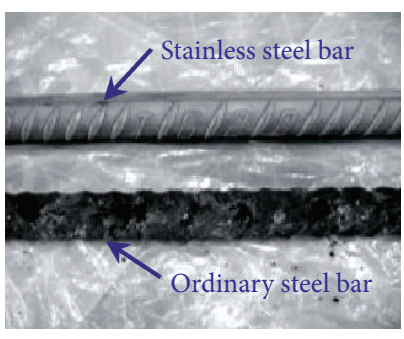

(a)

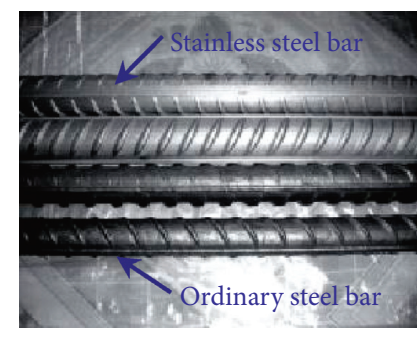

(b)

Figure 3: Comparison of the corrosion of stainless steel bars and ordinary steel bars: (a) before rust removal and (b) after rust removal.

thickness of the concrete cover, the embedded and bonding lengths of steel bars, and the configurations of stirrups have not been unified all over the world. However, the beam test on bond behavior between concrete and steel bars can better reflect the combined action of shear and bending moments on concrete beams [56].

Other experimental results also proved that the bond behavior between concrete and stainless steel bars are basically similar to the bond behavior between concrete and ordinary steel bars $[57,58]$. However, another study reported that the bond behavior between stainless steel bars and concrete was better than the bond behavior between ordinary steel bars and concrete $[31,59]$. Nevertheless, some other works found that the bond behavior between stainless steel bars and concrete was worse than the bond behavior between ordinary steel bars and concrete, implying that the anchorage, or rather the lap length, of stainless steel bars in concrete should be larger than that of ordinary steel bars in concrete [60-63]. In addition, relevant studies all agree that the average bond strength between stainless steel bars and concrete enlarges with the increase in concrete strength [57, 59, 62, 63], but there are differences in the influence of the diameter of steel bars on the bond strength [35, 56, 59, 61, 62]. For example, the test results of [63] demonstrated that the ultimate bond strength between stainless steel bars and concrete was about $28 \%$ lower than that of the ultimate bond strength between ordinary steel bars and concrete; the bond strength also declined more rapidly, and the residual bond strength was lower. Furthermore, it is pointed out that when Eurocode 2 [13] and fib model code 2010 (MC 2010) [14] are directly applied to the stainless steel-reinforced concrete, the actual bond strength is underestimated. Therefore, on the basis of the bond stressslip constitutive behavior between steel bars and concrete under a monotonic load in MC 2010, which occurred as pull-out failure, a modified model suitable for stainless steel bars is proposed to enhance the utilization efficiency of stainless steel bars. The constitutive curves of the two models are plotted in Figure 4. In this figure, the MC 2010 model is expressed by equation (1), in which $\tau_{b \max }$ is the maximum bond stress and $\tau_{b f}$ indicates the residual bond stress. When $0 \leq s \leq s_{2}$, the expression of the modified model is similar to that of the MC 2010 model; when $s \geq s_{2}$, $\tau_{b}=\tau_{b \max }\left(S_{2} / S\right)^{\alpha_{1}}$ is adopted in the modified model. The values of the relevant parameters are also listed in Table 1.

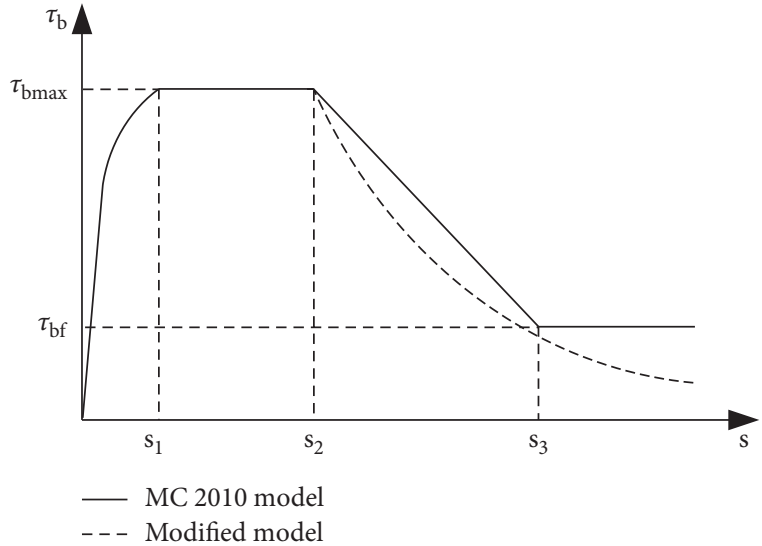

Figure 4: Comparison of bond stress-slip models.

TABLE 1: The parameter values of the bond stress-slip models.

\begin{tabular}{lcc}
\hline Parameter & MC 2010 & Modified model \\
\hline$\tau_{b \max }$ & $2.5 \sqrt{f_{\mathrm{cm}}}$ & $2.4 \sqrt{f_{\mathrm{cm}}}$ \\
$s_{1}$ & $1.0 \mathrm{~mm}$ & $0.5 \mathrm{~mm}$ \\
$s_{2}$ & $2.0 \mathrm{~mm}$ & $2.0 \mathrm{~mm}$ \\
$s_{3}$ & $c_{\text {clear }}$ & - \\
$\alpha$ & 0.4 & 0.4 \\
$\alpha_{1}$ & - & 0.9 \\
$\tau_{\text {bf }}$ & $0.4 \tau_{b \max }$ & - \\
\hline
\end{tabular}

Note: $f_{\mathrm{cm}}$ is the compressive strength of concrete cylinders and $c_{\text {clear }}$ denotes the clear distance between the adjacent rebars.

$$
\tau_{b}= \begin{cases}\tau_{b}=\tau_{b \max }\left(S_{2} / S\right)^{\alpha}, & 0 \leq s \leq s_{1}, \\ \tau_{b \max }, & s_{1} \leq s \leq s_{2}, \\ \tau_{b \max }-\frac{\left(\tau_{b \max }-\tau_{b f}\right)\left(s-s_{2}\right)}{\left(s_{3}-s_{2}\right)}, & s_{2} \leq s \leq s_{3}, \\ \tau_{b f}, & s_{3}<s .\end{cases}
$$

From the above analyzes, it is inferred that, owing to various material properties and different standards for the specimens used in the central pullout test, there are no consistent conclusions on the difference in the properties of the bond between concrete and stainless steel bars and those 
of the bond between concrete and ordinary steel bars. The stainless steel bars produced according to various national standards have different interfacial bonding behaviors because of the differences in their surface characteristics, yield strength, and postyield properties. Hence, in future studies, it is necessary to design a test scheme elaborately so as to determine the mechanism for the bond behavior of stainless steel bars experimentally. Considering that the test data are relatively scattered, the existing test data are classified to establish a test database of the bond performance of stainless steel bars. The probabilistic and statistical characteristics of the existing data are obtained and used as a prior distribution, and then, the statistical parameters of the influencing factors are deduced for the performance of the bond of concrete to stainless steel reinforcements by the Bayesian statistical method. Afterward, these parameters are employed for establishing the bond stress-slip constitutive relation of stainless steel-reinforced concrete.

\section{Mechanical Behavior of Stainless Steel- Reinforced Concrete Members}

4.1. Stainless Steel-Reinforced Concrete Beams. Compared with ordinary steel bars, the elastic modulus of stainless steel bars is generally lower, leading to the higher deformation of concrete beams and to the formation of wider cracks in concrete beams in the normal usage stage [7, 32, 55-57]. Markeset et al. pointed out that if the limited maximum crack width of ordinary steel-reinforced concrete members ranges from 0.10 to $0.20 \mathrm{~mm}$, then that of the stainless steelreinforced concrete members can be extended to the range of $0.30-0.40 \mathrm{~mm}$ [3]. Moreover, stainless steel-reinforced concrete beams have minimal requirements in terms of the thickness of the concrete cover, which is conducive to fulfilling the requirements of the maximum allowable crack width and can reduce the amount of the reinforcement to achieve the goal of lowering the project cost [32].

The studies on the mechanical properties of stainless steel-reinforced concrete beams under a static load have chiefly focused on the flexural properties of the normal section. For example, experimental results demonstrated that the failure mode of the normal section of stainless steelreinforced concrete beams was similar to that of ordinary steel-reinforced concrete beams, so the plane section assumption is still applicable to stainless steel-reinforced concrete beams $[31,55,64,65]$. Furthermore, comparing the experimental results of stainless steel-reinforced concrete beams with those of ordinary steel-reinforced concrete beams revealed that when other parameters were identical, the bending failure process and mode of the normal section of stainless steel-reinforced concrete beams were basically similar to those of the ordinary steel-reinforced concrete beams, and all beams experienced four typical stages of elasticity, cracking, yielding, and failure, as shown in Figure 5 [65]. In Figure 5, PKW1 is the ordinary steel-reinforced concrete beam, and $\mathrm{BKW} 1$ and $\mathrm{BKW} 2$ represent the stainless steel-reinforced concrete beams. In addition, experimental results of the shear behavior of two simply supported concrete beams with stainless steel bars were presented in [65], but no systematic conclusions were drawn.

It is necessary to assess whether the current design code formulas for calculating ordinary steel-reinforced concrete structures are still applicable to stainless steel-reinforced concrete structures. Van den berg and Liang found that when the strain of stainless steel bars was larger than 0.001 , the maximum crack width calculated by the formulas of codes British BS 8110 and American ACI 318 M-89 was significantly smaller than the measured value [7]. Furthermore, other works reported that the formulas of codes GB 50010 and ACI 318 were conservative in predicting the flexural capacity of the stainless steel-reinforced concrete beams [34, 64-66]. However, it is not necessarily safe to apply the Eurocode 2 material model directly to the stainless steel-reinforced concrete members, and the proper consideration of the strain hardening characteristics of stainless steel bars in the design process is conducive to improving the flexural capacity and ductility of concrete beams $[67,68]$. In addition, Zhang et al. [64] found that the deflection of stainless steel-reinforced concrete beams calculated by the formula of code American ACI 318 was better than that predicted by the formula of code Chinese GB 50010. It was also reported that the expressions of the average crack width and the short-term deflection described in GB 50010-2010 were suitable for stainless steel-reinforced concrete beams [66].

At present, there are few studies on the seismic and fatigue performance of stainless steel-reinforced concrete flexural members. Test results showed that the yield displacement, ultimate displacement, and displacement ductility coefficient of stainless steel-reinforced concrete beams under low cyclic loading were significantly higher than those of ordinary steel-reinforced concrete beams. Furthermore, the fatigue damage accumulation, crack development, deflection change, and stiffness attenuation of stainless steel bars in concrete beams under fatigue loads were largely concentrated in the early stages of loading, while the changes of the above indices run through the whole loading process for the ordinary steel-reinforced beams. Moreover, stainless steel-reinforced concrete beams showed characteristics of less damage accumulation and slow stiffness degradation [69-71].

4.2. Stainless Steel-Reinforced Concrete Columns. The results of eccentric compression tests confirmed that the strain distribution in the section of stainless steel-reinforced concrete columns conformed to the assumption of the plane section, and their failure mode was similar to that of the ordinary steel-reinforced concrete columns [72, 73]. The whole loading process could be divided into an elastic stage, a cracking stage, and a failure stage, but the lower elastic modulus and better ductility of stainless steel bars led to a greater deformation of the column when they were damaged. On the basis of the mesoscopic numeric model of stainless steel-reinforced concrete members under eccentric loads, Wu obtained the simulated results which were in good agreement with the experimental phenomena [74]. 


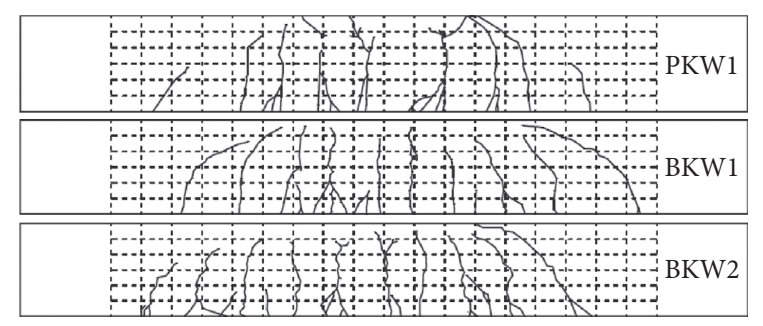

(a)

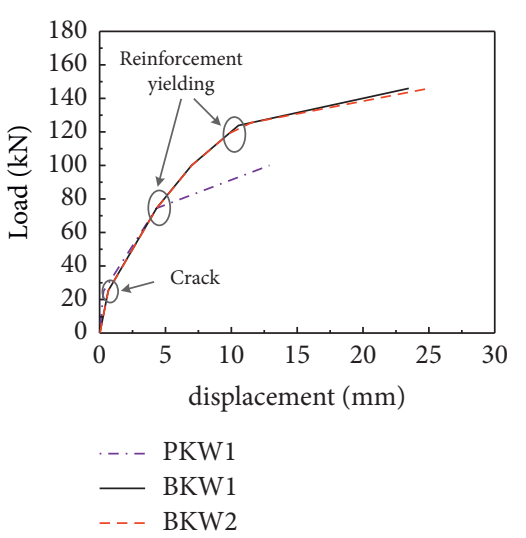

(b)

FIGURE 5: Comparison of the bending failure of the concrete beams reinforced with stainless steel bars and ordinary steel bars: (a) the crack distribution and (b) the load-displacement curve.

The results of low cyclic loading tests also demonstrated that the failure mode and load-displacement hysteretic curves of the stainless steel-reinforced concrete columns were similar to those of the ordinary steel-reinforced concrete columns, and they had good seismic performance $[75,76]$. Some test results of [76] are shown in Figure 6, in which SKC-1 and SKC-5 represent the stainless steel-reinforced concrete columns, DBC- 1 and DBC-2 indicate the ordinary steel-reinforced concrete columns. The test parameters of the two types of the members such as the yield strength and tensile strength of the reinforcement are basically identical. Moreover, through the analysis of the test results, it was found that the equivalent viscous damping coefficients $\left(h_{e}\right)$ at yield, at peak, and at failure of the stainless steel-reinforced concrete columns were, respectively, 32\%, $31 \%$, and $3 \%$ larger than those of the ordinary steel-reinforced concrete columns, indicating that the energy dissipation capacity of stainless steel-reinforced concrete columns was better. The nonlinear finite element program OPENSEES was also utilized to analyze the seismic performance parameters of stainless steel-reinforced concrete columns, and the normal section restoring force model was constructed. The results showed that the factors influencing the seismic performance of the stainless steel-reinforced concrete columns and their effects were similar to those of the ordinary steel-reinforced concrete columns [77, 78].

From the above analyzes, it can be inferred that there are few experimental research studies and design theories on the mechanical properties of reinforced concrete beams and columns, and the design guidance specifications of stainless steel-reinforced concrete structures have not been published worldwide. However, the lower elastic modulus of stainless steel bars and the remarkable strain hardening characteristics of the stainless steel-reinforced concrete structures can lead to larger deformation and cracks in the normal usage stage. In addition, there is no obvious yielding platform for stainless steel bars, so the theoretical models of calculating the bearing capacity of members which require the plastic stress redistribution are no longer applicable. Furthermore, the stress-strain curves of the stainless steel bars under tension and compression are asymmetric, which further complicates the calculation of the bearing capacity of the columns under eccentric compression. Therefore, relevant research studies need to be conducted in the future to provide a reliable support for the design of stainless steelreinforced concrete structures.

\section{Engineering Applications of Stainless Steel- Reinforced Concrete Structures}

The earliest application of stainless steel-reinforced concrete structures can be traced back to the Progresso Pier in Mexico, which was built between 1937 and 1941 [79]. Although it has been exposed to a hot and humid marine environment for a long time, no large-scale maintenance has been carried out, and no obvious deterioration has been found in more than 60 years of service. By contrast, a bridge made of ordinary steel-reinforced concrete which was built to the west of the trestle at a distance of only about $200 \mathrm{~m}$ in the 1960s could not be repaired and was demolished in 1982 due to the serious corrosion of the reinforcement, as shown in Figure 7. In recent years, with the increasing demand for the more durable, efficient, and sustainable development of structures and infrastructures, stainless steel-reinforced concrete has widely been used in practical projects such as the Garden State Parkway Bridge, the Haynes Inlet Slough Bridge, and the Brooklyn Bridge in the United States, the Cradlewell Underpass, the Guildhall Yard East project, and the Aiit Chonoglais Bridge in the United Kingdom, the Church St. Bridge and the Hurdman Bridge in Canada, the Sheik Zayed Bridge in the United Arab Emirates, and the Broadway Bridge in Ireland [4, 44, 80, 81].

In China, the application of stainless steel-reinforced concrete structures chiefly includes the $3.2 \mathrm{~km}$ long bridge in the Hong Kong section of Shenzhen. The Western Corridor Bridge brought into use in 2007 also adopted stainless steel bars. Furthermore, the Stonecutters Bridge in Hong Kong was complete and came into use in 2009, and stainless steel bars were arranged in the outermost layer of the multilayer ordinary bars to achieve stiff resistance to corrosion in the 


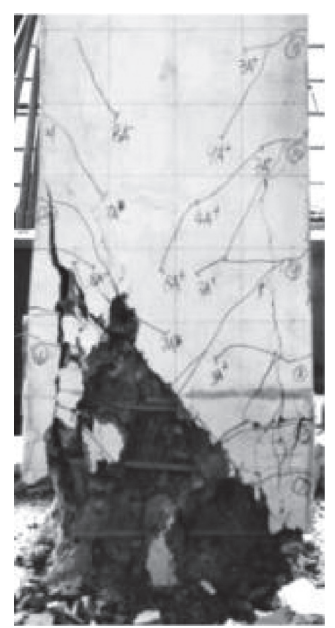

(a)

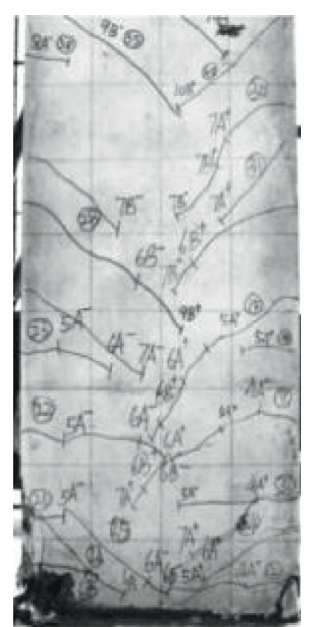

(b)

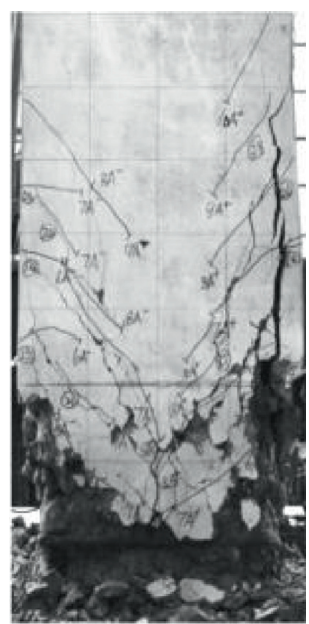

(c)

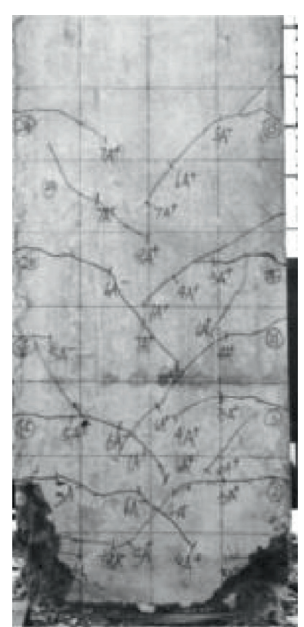

(d)

FIGURE 6: Comparison of the failure patterns of the concrete beams reinforced with stainless steel bars and ordinary steel bars: (a) SKC-1; (b) SKC-5; (c) DBC-1; (d) DBC-2.

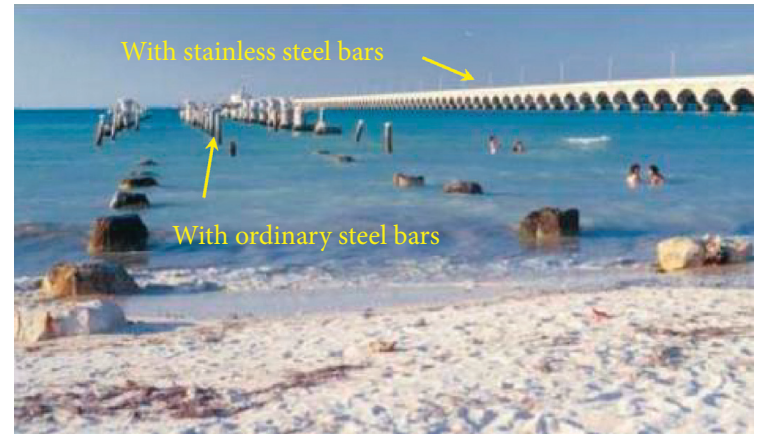

Figure 7: The Progresso pier in Mexico.
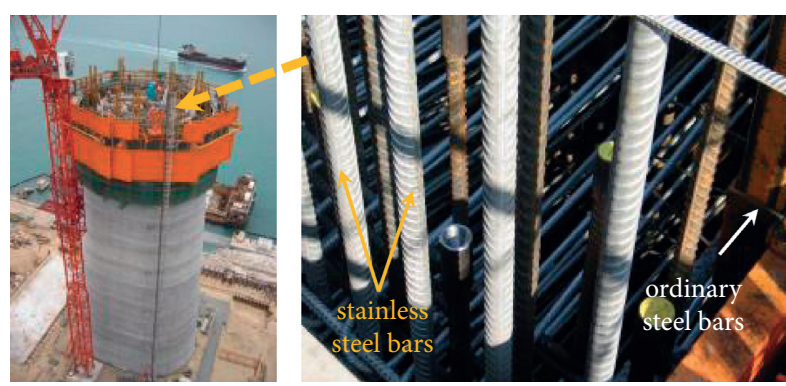

Figure 8: The mixed reinforcement grid of the Stonecutters Bridge in Hong Kong.

pier, as shown in Figure 8 [82]. In addition, for the Yuanlixi Bridge strengthened in 2011, some columns of piers were encased with stainless steel-reinforced concrete; the Mangrove Bridge, which was complete in 2014, adopted stainless steel-reinforced concrete structures in the right lower frame of pier No. 5 of the approaching bridge, $1.5 \mathrm{~m}$ at the top of the pile foundation and the tie beam [4]. Moreover, the platform, tower base, and pier body of the Hong KongZhuhai-Macao Bridge brought into operation in 2018 were made of domestic, duplex, and stainless steel bars, realizing the application of stainless steel bars in bridge construction in China for the first time [44]. Stainless steel bars were also used in the tie beam of the bearing platform of the main tower of the Wuhan Qingshan Yangtze River Bridge which was complete in 2020 [83].

\section{Conclusions}

This paper summarizes the progress of the research into stainless steel-reinforced concrete structures from four aspects: the mechanical properties and corrosion resistance of stainless steel bars, the performance of the bond between stainless steel bars and concrete, the mechanical properties of stainless steel-reinforced concrete members, and the engineering applications of stainless steel reinforcements. The following main conclusions can be drawn from the above discussion:

(1) Stainless steel bars enjoy the advantages of high strength, high ductility, strong resistance to low temperatures, and stiff resistance to corrosion compared with ordinary steel bars. Their proportional limit and elastic modulus are both relatively low, and there is no obvious yielding platform in the stress-strain curves. The difference between their tensile strength and compressive strength is large, and both are far larger than their yield strength. Moreover, stainless steel bars exhibit significant strain hardening characteristics. Compared to other types of stainless steel bars, austenitic stainless steel bars have low permeability which suits them to electronic sensitive buildings, military engineering, and other fields requiring diamagnetism.

(2) Owing to the different material properties and the large dispersion of the test results, it is still too early to reach a firm conclusion on the difference in the properties of the bond between concrete and stainless steel bars and those of the bond between concrete and ordinary steel bars. Thus, in future 
studies, the standards for the specimens should be unified as much as possible, and advanced test technologies should be used. Then, the Bayesian statistical method should be employed to deduce the statistical parameters of the factors influencing the performance of the bond between stainless steel bars and concrete, and the stress-slip constitutive behavior of the bond between stainless steel bars and concrete should be developed.

(3) The elastic modulus of stainless steel bars is generally low, which leads to the greater deformation of concrete beams and the formation of wider cracks in concrete beams in the normal usage stage compared with ordinary steel bars. Furthermore, the remarkable strain hardening characteristics and high ductility of stainless steel bars make the loading process of stainless steel-reinforced concrete beams different from that of ordinary steel-reinforced concrete beams. When high-strength stainless steel bars are used as the longitudinal tensile reinforcement, the influence of the above mechanical properties on the mechanical properties of concrete beams has not systematically been studied. Moreover, the calculation methods for the deflection, maximum crack width, and flexural capacity of the normal section of high-strength, stainless steel-reinforced, and concrete beams under a short-term load need to be further investigated.

(4) There is still a lack of reliable test data on the stress state and design strength index of stainless steel bars. Therefore, the calculation method for the shear capacity of the inclined section still needs to be examined for the concrete beams adopting high-strength stainless steel bars as the longitudinal tensile bars and the shear stirrups. This especially stands for the thin-web beams in which web shear cracks may form earlier than bending shear cracks when the requirements for the width of diagonal cracks in structures in the normal service stage are taken into account.

\section{Data Availability}

The data used to support the findings of this study are included in the article.

\section{Conflicts of Interest}

The authors declare no conflicts of interest.

\section{Acknowledgments}

This research was financially supported by the National Natural Science Foundation of China (Grant no. 52178183), the Science and Technology Innovation Program of Hunan Province of China (Grant no. 2020RC4049), and the Scientific Research Foundation for the Talent Introduction of the Central South University of Forestry Science and Technology (Grant no. 2018YJ037).

\section{References}

[1] C. Q. Li and R. E. Melchers, "Time-dependent risk assessment of structural deterioration caused by reinforcement corrosion," ACI Structural Journal, vol. 102, no. 5, pp. 754-762, 2005.

[2] B. R. Hou, X. G. Li, X. M. Ma et al., "The cost of corrosion in China," Npj Materials Degradation, vol. 1, no. 1, pp. 1-10, 2017.

[3] G. Markeset, S. Rostam, and O. Klinghoffer, Guide for the Use of Stainless Steel Reinforcement in concrete Structures, Norwegian Building Research Institute, Oslo, Norway, 2006.

[4] J. Q. Zhang, C. C. Li, X. H. Zheng, and J. W. Zhang, Research on Stainless Steel Reinforced concrete Structure, China Communications Press Co. Ltd, Beijing, China, 2015.

[5] J. M. Mcgurn, Stainless Steels Reinforcing Bars in concrete, in Proceedings of the International Conference on Corrosion and Rehabilitation of Reinforced concrete Structures, Orlando, FL, USA, December1998.

[6] A. Knudsen, "Cost effective enhancement of durability of concrete structures by intelligent use of stainless steels reinforcement," in Proceedings of the International Conference on Corrosion and Rehabilitation of Reinforced concrete Structures, Orlando, FL, USA, December1998.

[7] G. J. Van den berg and A. H. Liang, "A study and research of stainless steel in concrete structure," Architectural Technology, vol. 31, no. 2, pp. 105-107, 2000.

[8] S. D. Cramer, B. S. Covino, S. J. Bullard et al., "Corrosion prevention and remediation strategies for reinforced concrete coastal bridges," Cement and Concrete Composites, vol. 24, no. 1, pp. 101-117, 2002.

[9] D. V. Val and M. G. Stewart, "Life-cycle cost analysis of reinforced concrete structures in marine environments," Structural Safety, vol. 25, no. 4, pp. 343-362, 2003.

[10] American Society for Testing and Materials, A955/A995 M: 2004 Standard specification for deformed and plain stainless steel bars for concrete reinforcement, ASTM Internationl, West Conshohocken, PA, USA, 2004.

[11] Japanese Industrial Standards, JIS G4322-2008 Stainless Steel Bars for concrete Reinforcement, Japanese Industrial Standards, 2008.

[12] British Standards Institution, B. S. 6744:2001+A2: 2009 Stainless Steel Bars for the Reinforcement and Use in concrete Requirements and Test Methods, British Standards Institution, Chennai, India, 2009.

[13] European Committee for Standardization, Design of concrete Structures: Part 1-1: General Rules and Rules for Buildings: EN 1992-1-1:2004 Eurocode 2, The European Unoin, Maastricht, Netherlands, 2004.

[14] International Federation for Structural Concrete, Fib Bulletin 55: CEB-FIP Model Code 2010, First Complete Draft, International Federation for Structural Concrete, Lausanne, Switzerland, 2010.

[15] American Concrete Institute, Building Code Requirements for Structural Concrete and Commentary, ACI, Farmington Hills, MICH, USA, 2019.

[16] Gb/T 33959-2017, Stainless Steel Bars for the Reinforcement of concrete, Standards Press of China, Beijing, China, 2017.

[17] CCES 01-2004, Design and Construction Guide for Durability of concrete Structures (Revised Edition of 2005), China Architecture \& Building Press, Beijing, China, 2005.

[18] E. Mirambell and E. Real, "On the calculation of deflections in structural stainless steel beams: an experimental and 
numerical investigation," Journal of Constructional Steel Research, vol. 54, no. 1, pp. 109-133, 2000.

[19] K. J. R. Rasmussen, "Full-range stress-strain curves for stainless steel alloys," Journal of Constructional Steel Research, vol. 59, no. 1, pp. 47-61, 2003.

[20] W. M. Quach, J. G. Teng, and K. F. Chung, "Three-stage fullrange stress-strain model for stainless steels," Journal of Structural Engineering, vol. 134, no. 9, pp. 1518-1527, 2008.

[21] L. Gardner, "The use of stainless steel in structures," Progress in Structural Engineering and Materials, vol. 7, no. 2, pp. $45-55,2005$.

[22] D. Y. Ye, S. Matsuoka, N. Nagashima, and N Suzuki, "The lowcycle fatigue, deformation and final fracture behavior of an austenitic stainless steel," Materials Science and Engineering A, vol. A415, no. 1/2, pp. 104-117, 2006.

[23] A. Dutta, S. Dhar, and S. K. Acharyya, "Material characterization of SS 316 in low-cycle fatigue loading," Journal of Materials Science, vol. 45, no. 7, pp. 1782-1789, 2010.

[24] Y. Q. Wang, T. Chang, and Y. J. Shi, "Experimental study on constitutive relationship in austenitic stainless steel under cyclic loading," Journal of Southeast University, vol. 42, no. 6, pp. 1175-1179, 2012.

[25] J. Chen and B. Young, "Stress-strain curves for stainless steel at elevated temperatures," Engineering Structures, vol. 28, no. 2, pp. 229-239, 2006.

[26] L. Gardner, A. Insausti, K. T. Ng, and M. Ashraf, "Elevated temperature material properties of stainless steel alloys," Journal of Constructional Steel Research, vol. 66, no. 5, pp. 634-647, 2010.

[27] Y. Sakumoto, T. Nakazato, and A. Matsuzaki, "High-temperature properties of stainless steel for building structures," Journal of Structural Engineering, vol. 122, no. 4, pp. 399-406, 1996.

[28] S. G. Fan, J. C. Zheng, W. J. Sun, X. F Xia, and M. J Liu, "Experimental investigation on mechanical properties of S30408 austenitic stainless steel at elevated temperatures," Engineering Mechanics, vol. 34, no. 4, pp. 167-176, 2017.

[29] K. Barat, H. N. Bar, D. Mandal, H. Roy, S. Sivaprasad, and S. Tarafder, "Low temperature tensile deformation and acoustic emission signal characteristics of AISI 304LN stainless steel," Materials Science and Engineering, vol. 597, no. 12, pp. 37-45, 2014.

[30] G. J. Van den berg, "The effect of the non-linear stress-strain behaviour of stainless steels on member capacity," Journal of Constructional Steel Research, vol. 54, no. 1, pp. 135-160, 2000.

[31] H. T. Geng, "Experimental Study on Mechanical Properties of Stainless Steel Bars and Members on Bridges," Master Thesis, Zhengzhou University, Zhengzhou, China, 2013.

[32] E. Medina, J. M. Medina, A. Cobo, and D. M. Bastidas, "Evaluation of mechanical and structural behavior of austenitic and duplex stainless steel reinforcements," Construction and Building Materials, vol. 78, pp. 1-7, 2015.

[33] C. C. Li, M. H. Mu, C. X. Nie, Q. F. Li, and H. M. Wang, "Mechanical and processing properties of stainless steel bar," Journal of Highway and Transportation Research and Development, vol. 33, no. 12, pp. 1-5, 2016.

[34] D. Gao, H. Zhang, X. F. Wang, and Y. Zhao, "Experimental investigation on flexural capacity of reinforced concrete beams with high-strength stainless steel bars," Building Science, vol. 34, no. 5, pp. 40-43, 2018.

[35] J. W. Wang, Experimental Study on Bond Properties of Stainless Steel and concrete," Master Thesis, Zhengzhou University, Zhengzhou, China, 2018.
[36] S. Alih and A. Khelil, "Behavior of inoxydable steel and their performance as reinforcement bars in concrete beam: experimental and nonlinear finite element analysis," Construction and Building Materials, vol. 37, pp. 481-492, 2012.

[37] P. Gu, S. Elliott, J. J. Beaudoin, and B Arsenault, "Corrosion resistance of stainless steel in chloride contaminated concrete," Cement and Concrete Research, vol. 26, no. 8, pp. 1151-1156, 1996.

[38] S. Tsouli, A. G. Lekatou, E. Siozos, and S. Kleftakis, "Accelerated corrosion performance of AISI 316L stainless steel concrete reinforcement used in restoration works of ancient monuments," in Proceedings of the MATEC Web of Conferences, Opole, Porland, April 2018.

[39] X. G. Feng, X. Lu, Y. Wang, J. Qian, and X. Y. Lu, "Corrosion rate of stainless steel reinforcements in coral concrete prepared with seawater," Journal of Building Materials.

[40] X. Wu, L. Li, H. Li, B. Li, and Z. Ling, "Effect of strain level on corrosion of stainless steel bar," Construction and Building Materials, vol. 163, pp. 189-199, 2018.

[41] X. Wu, D. Ye, H. Li, and H. Yu, "Corrosion characteristics of S23043 duplex stainless steel bars," Construction and Building Materials, vol. 178, pp. 135-143, 2018.

[42] M. A. Islam, B. P. Bergsma, and C. M. Hansson, "Chlorideinduced corrosion behavior of stainless steel and carbon steel reinforcing bars in sound and cracked concrete," Corrosion, vol. 69, no. 3, pp. 303-312, 2013.

[43] L. Chen, Y. Qu, and Y. B. Tang, "Critical chloride concentration of stainless steels in simulated concrete pore solutions," Corrosion \& Protection, vol. 35, no. 5, pp. 446-449, 2014.

[44] Q. Jing, X. Fang, J. X. Ni, Y. B. Tang, and X. Fang, "Use of 2304 Stainless steel reinforcement in Hong Kong-Zhuhai-Macau bridge-corrosion behaviors of 2304 stainless steel reinforcement," Journal of Highway and Transportation Research and Development, vol. 34, no. 10, pp. 51-56, 2017.

[45] J. Y. Ling, Corrosion Resistance of a New Type Stainless Steel and Mechanical Properties of Stainless Steel Reinforced concrete Members, Master Thesis, Zhejiang University, Hangzhou, China, 2018.

[46] R. D. Moser, P. M. Singh, L. F. Kahn, and K. E. Kurtis, "Chloride-induced corrosion resistance of high-strength stainless steels in simulated alkaline and carbonated concrete pore solutions," Corrosion Science, vol. 57, no. 2, pp. 241-253, 2012.

[47] C. B. Van Niejenhuis, S. Walbridge, and C. M. Hansson, "The performance of austenitic and duplex stainless steels in cracked concrete exposed to concentrated chloride brine," Journal of Materials Science, vol. 51, no. 1, pp. 362-374, 2016.

[48] Rasheeduzzafar, F. H. Dakhil, M. A. Bader, and M. M. Khan, "Performance of corrosion resisting steel in chloride bearing concrete," ACI Materials Journal, vol. 89, no. 5, pp. 439-448, 1992.

[49] K. W. J. Treadaway, R. N. Cox, and B. L. Brown, "Durability of corrosion resisting steels in concrete," Proceedings - Institution of Civil Engineers, vol. 86, no. 2, pp. 13-27, 1989.

[50] B. Da, H. F. Yu, H. Y. Ma, and Z. Wu, "Anti-corrosion performances of different types of rebars in coral aggregate seawater concrete," Materials Reports, vol. 33, no. 6, pp. 2002-2008, 2019.

[51] X. H. Zheng, C. C. Li, F. Yang, B. Huang, and H. M. Wang, "Corrosion resistant performance of stainless steel bar," Journal of Highway and Transportation Research and Development, vol. 33, no. 12, pp. 6-14, 2016. 
[52] D. B. Mcdonald, D. W. Pfeifer, and M. R. Sherman, Corrosion Evaluation of Epoxy-Coated, Metallic-Clad and Solid Metallic Reinforcing Bars in concrete, U.S. Department of Transportation Federal Highway Administration, McLean, Virginia, FHWA-RD-98-153, 1998.

[53] J. T. Pérez-Quiroz, J. Terán, M. J. Herrera, M. Martínez, and J. Genescá, "Assessment of stainless steel reinforcement for concrete structures rehabilitation," Journal of Constructional Steel Research, vol. 64, no. 11, pp. 1317-1324, 2008.

[54] J. P. Seibert, Galvanic Corrosion Aspects of Stainless and Black Steel Reinforce, Master Thesis, Queen's University, Kingston, New Yrok, USA, 1998.

[55] Y. Zhou, Performance of Stainless-Carbon Steel Bars Reinforced concrete Structure, Master Thesis, Zhejiang University, Hangzhou, China, 2017.

[56] J. J. Jiang, J. Li, and W. L. Jin, Advanced concrete Structure Theory, pp. 64-82, China Architecture \& Building Press, Beijing, China, 2007.

[57] C. C. Li, W. N. He, J. Lu, and H. T. Geng, "Bonding performance of stainless steel bars and concrete," Journal of Highway and Transportation Research and Development, vol. 33, no. 12, pp. 15-20, 2016.

[58] M. Pauletta, N. Rovere, N. Randl, and G. Russo, "Bond-slip behavior between stainless steel rebars and concrete," Materials, vol. 13, p. 979, 2020.

[59] Y. N. Wang, Experimental Study on Bonding Properties of Large Diameter Stainless Steel Reinforced concrete, Master Thesis, Shenyang Jianzhu University, Shenyang, China, 2019.

[60] Research Annual Reports, Department of transportation, Michigan Technological University, Michigan, USA, 2003.

[61] Y. H. Guo, Experimental Study on Bond Properties between Stainless Steel and concrete, Master Thesis, Shenyang Jianzhu University, Shenyang, China, 2015.

[62] B. Lu, "Study on Bonding Properties between Austenitic Stainless Reinforcement Steel and Concrete, Master Thesis, Shenyang Jianzhu University, Shenyang, China, 2018.

[63] M. Rabi, K. A. Cashell, R. Shamass, and P Desnerck, "Bond behavior of austenitic stainless steel reinforced concrete," Engineering Structures, vol. 221, Article ID 111027, 2020.

[64] G. X. Zhang, Y. S. Xu, and Z. Ding, "Experimental study on flexural behavior of concrete beams reinforced with stainless steel," Railway Engineering, no. 2, pp. 13-15, 2008.

[65] Q. F. Li, W. Guo, C. H. Liu, Y Kuang, and H . Geng, "Experimental and theoretical studies on flexural performance of stainless steel reinforced concrete beams," Advances in Civil Engineering, vol. 2020, Article ID 4048750, 2020.

[66] J. B. Yang, Experimental Study on Crack Widths of Reinforced concrete Beams with Stainless Steel Bars, Master Thesis, Chongqing University, Chongqing, China, 2019.

[67] M. Rabi, K. A. Cashell, and R. Shamass, "Flexural analysis and design of stainless steel reinforced concrete beams," Engineering Structures, Article ID 109432, 2019.

[68] M. Geromel and O. Mazzarella, "Experimental and analytical assessment of the behavior of stainless steel reinforced concrete beams," Materials and Structures, vol. 38, no. 2, pp. 211-218, 2005.

[69] G. X. Zhang, F. Zhao, Z. Zhang, H. Zhang, X. Zhou, and D. Rao, "Experimental study on the seismic performance of the stainless steel reinforced concrete beams," China Railway Science, vol. 31, no. 5, pp. 35-40, 2010.

[70] J. W. Huang, Experimental Study on Fatigue Performance of concrete with Stainless Steel Bars in Bridge, Master Thesis, Guangdong University of Technology, Guangzhou, China, 2013.
[71] L. Gu, Experimental Study on Vibration Fatigue Residual Bearing Capacity of Stainless Steel Reinforced concrete Beams, Master Thesis, Shenyang Jianzhu University, Shenyang, China, 2018.

[72] H. L. Wang, J. Y. Ling, X. Y. Sun, and X. B. Li, "Performance of stainless steel reinforced concrete column under small eccentric compression," Journal of Zhejiang University, vol. 52, no. 10, pp. 1919-1925, 2018.

[73] Y. L. Zhang, Experimental Study on Mechanical Properties of Stainless Steel Reinforced concrete Columns, Master Thesis, Zhengzhou University, Zhengzhou, China, 2019.

[74] X. P. Wu, Analysis of Compressive Bearing Capacity of Stainless Steel Reinforced concrete Based on Micro-mechanics, Master Thesis, Zhengzhou University, Zhengzhou, China, 2019.

[75] Z. H. Zhang, Experimental Study on Seismic Performance of Stainless Steel Reinforced concrete Columns, Master Thesis, Guangdong University of Technology, Guangzhou, China, 2010.

[76] Y. Zhao, C. Zhang, and X. F. Wang, "Experimental research on seismic behaviors of concrete columns with high-ductility stainless steel reinforcement," Journal of Tongji University, vol. 48, no. 6, pp. 803-810, 2020.

[77] C. W. Wang, Numerical Analysis and Restoring Force Model Research of Seismic Behavior of concrete Columns with Stainless Steel Bars, Master Thesis, Guangdong University of Technology, Guangzhou, China, 2012.

[78] J. N. Liu, Study on Resilience Behavior of concrete Columns with Stainless Steel Bars, Master Thesis, Chongqing University, Chongqing, China, 2019.

[79] Nickel Institute, "Progreso pier built with nickel-containing stainless steel," 2018, https://www.stainlesssteelrebar.org/ applications/progreso-pier/.

[80] H. X. Yuan, Y. Q. Wang, and Y. J. Shi, "Preliminary Study and application prospect of stainless steel reinforced concrete," Building Science, vol. 27, no. 5, pp. 101-105, 2011.

[81] China ferroalloys net, "Quiet evolution-infrastructures start to use a large number of stainless steel,” 2016, http://www.ferroalloys.cn/News/Details/227797.

[82] Highway Department, the government of Hong Kong special administrative region Stonecutters Bridge: http://www. Stonecuttersbridge.net.

[83] Z. H. Liao, Wuhan Qingshan Yangtze River bridge: the world's highest 'A', Wuhan, China, 2018. 